\title{
COMunicación
}

\section{Comparación entre Palpación Testicular y ELSA Indirecto en el Diagnóstico de Brucelosis Ovina}

\author{
Comparison between Testicular Palpation And Indirect ELISA for the \\ Diagnosis of Ovine Brucellosis
}
Ignacio Troncoso T. ${ }^{1,4}$, Judith González A. ${ }^{1}$, Felipe Navarrete A. ${ }^{2}$, Alejandro Lagos M. ${ }^{2}$, Christof Fischer Wiethuchter ${ }^{1,3}$

\section{Resumen}

El diagnóstico de la brucelosis ovina en Chile se basa en el examen clínico de palpación testicular, con la posterior detección de la infección a través de pruebas serológicas, siendo la fijación de complemento, inmunodifusión en gel agar y ELISA indirecto las más utilizadas. El presente estudio se realizó en la Comuna de San Ignacio, VIII Región, con 40 carneros a fin de hacer una comparación diagnóstica entre la palpación testicular y ELISA indirecto para la detección de anticuerpos contra Brucella ovis en suero. Los resultados indicaron 12 (30.0\%) carneros positivos a la palpación testicular y 5 (12.5\%) a ELISA indirecto, donde el nivel de concordancia entre ambas pruebas diagnósticas fue pobre $(\mathrm{k}=0.0714)$, lo que implica que un carnero detectado clínicamente con epididimitis u orquitis no necesariamente estaría infectado con $B$. ovis.

Palabras clave: brucelosis, ELISA, palpación testicular, kappa

\section{Abstract}

The diagnosis of ovine brucellosis in Chile is based on clinical examination of the testicles and confirmed with a serological test, being the complement fixation test, agar gel immunodiffusion test and the indirect ELISA the most used. The present study was carried out in the Municipality of San Ignacio, VIII Chilean region in 40 rams with the aim of comparing two diagnostic tools: testicular

\footnotetext{
${ }^{1}$ Universidad Santo Tomás, Escuela de Medicina Veterinaria, Concepción, Chile

${ }^{2}$ Proyectos Asociativos de Fomento (PROFO) Ovino, Nuble, Chile

${ }^{3}$ Programa de Desarrollo Local (PRODESAL), San Ignacio, Chile

${ }^{4}$ E-mail: ignaciotroncoso@santotomas.cl
}

Recibido: 27 de febrero de 2014

Aceptado para publicación: 5 de setiembre de 2014 
palpation and indirect ELISA for the antibody detection against Brucella ovis. The results showed $12(30 \%)$ rams positive to testicular palpation and 5 rams $(12.5 \%)$ positive to ELISA, where the level of agreement between the two diagnostic tests was poor $(\mathrm{k}=0.0714)$. Positive rams to brucellosis based on testicular palpation are not necessarily infected with B. ovis.

Key words: brucellosis, ELISA, testicular palpation, kappa

\section{INTRODUCCIÓN}

La brucelosis es conocida como la principal causa de problemas reproductivos en la especie ovina, principalmente en carneros; causa inflamación de los testículos y del tracto reproductivo (epididimitis, vesiculitis seminal y orquitis). Es por lo tanto, motivo de eliminación de reproductores del predio. La enfermedad afecta en menor grado a las ovejas, pudiendo causar pérdidas reproductivas por muerte embrionaria y abortos esporádicos (Paolicchi, 2001).

El agente causal de la enfermedad es Brucella ovis, el cual fue aislado por primera vez en Nueva Zelandia en 1952 a partir de fetos abortados, y en 1953 fue aislado de carneros con epididimitis en Australia y Nueva Zelandia (Robles, 1998). En 1956 se le reporta por primera vez en América y en 1961 en Argentina en el semen de un carnero con epididimitis (Robles, 1998). Las primeras sospechas de la enfermedad en Chile se presentaron en ovinos de Magallanes (Tamayo et $a l .$, 1989), siendo la bacteria aislada por primera vez en 1968 (Zamora et al., 1977).

La principal medida de control para esta enfermedad es la realización de exámenes periódicos (palpación testicular y pruebas serológicas) de los carneros previo al inicio de la etapa reproductiva, a fin de proceder a su eliminación del rebaño, puesto que, son estos los principales diseminadores del agente dentro del predio (Pinochet et al., 1987).
Debido a que B. ovis se caracteriza por causar una enfermedad altamente contagiosa que repercute negativamente en la producción de ovinos, y considerando que no se disponen de datos cuantitativos en el país, el presente trabajo tuvo como objetivo determinar la posible presencia de $B$. ovis en tres predios de la Comuna de San Ignacio, VIII Región de Chile, así como determinar la valía de la palpación testicular en relación a la prueba de ELISA indirecta para el diagnóstico de brucelosis en los carneros.

\section{Materiales y Métodos}

\section{Lugar de Estudio y Animales}

El estudio se realizó en la comuna de San Ignacio, ubicada a $32 \mathrm{~km}$ al sur de la ciudad de Chillán. La comuna cuenta con 8885 cabezas de ovinos (INE, 2007). Se trabajó con 40 carneros de tres predios, todos con al menos un periodo de monta. Los animales era mayormente de raza Suffolk (37), pero también se incluyeron carneros Highlander (2) y Texel (1), con edades de 1.5 a 4 años, previo a la etapa de encaste y sin antecedentes de problemas reproductivos según registros.

\section{Examen Clínico}

El examen clínico fue realizado por un profesional experimentado, para lo cual el animal se dispuso en posición sentado sobre 
sus cuartos posteriores, erguido y con la cabeza levemente levantada. Los testículos fueron descendidos desde la zona inguinal hacia la bolsa escrotal con un suave movimiento de tracción. Los testículos y los epidídimos fueron palpados, y los resultados fueron catalogados según los siguientes criterios:

- Circunferencia escrotal: Una medida de $30 \mathrm{~cm}$ o más en carnerillos y de 32 cm o más en carneros adultos son consideradas adecuadas para una alta calidad espermática y producción de semen (Schoenian, 2011).

- Deslizabilidad: Los testículos deben deslizarse fácilmente dentro de la bolsa escrotal. La presencia de orquitis o adherencias testiculares reduce la deslizabilidad.

- Consistencia: El testículo normalmente presenta una consistencia tenso-elástica (se puede hundir la superficie con la punta de los dedos). Asimismo, la consistencia de los epidídimos (cabeza, cuerpo, cola) es tenso-firme-elástica (Chacón y Naranjo, 2007).

Fue considerado como positivo a la palpación testicular todo aquel animal que presentase aumento de tamaño, contorno anormal o consistencia firme al tacto de algunas de las partes del epidídimo (cabeza, cuerpo o cola), o a nivel testicular contase con atrofia unilateral o bilateral y adherencias entre las capas vaginal y parietal de la túnica vaginal (Robles, 2008).

\section{Muestras}

Se recolectaron muestras de sangre $(3$ ml) sin anticoagulante por animal, mediante venopunción de la vena yugular. Se registró la raza, edad y predio. La muestra se mantuvo a temperatura ambiente hasta la obtención del suero, aunque algunas fueron centrifugadas a $450 \mathrm{~g}$ por 15 minutos (Arévalo Hernández, 2004).
Cuadro 1. Escala para valoración de índice kappa (Pertega y Fernández, 2004)

\begin{tabular}{cl}
\hline Valor de k & Nivel de concordancia \\
\hline$<0.20$ & Pobre \\
$0.21-0.40$ & Débil \\
$0.41-0.60$ & Moderado \\
$0.61-0.80$ & Bueno \\
$0.81-1.00$ & Muy bueno \\
\hline
\end{tabular}

El suero se mantuvo a $-20^{\circ} \mathrm{C}$ y fue enviado, en una caja conservadora de frío, al laboratorio privado de servicios veterinarios Bioanálisis de la ciudad de Osorno (X Región). Las muestras se analizaron mediante ELISA indirecto (CHEKIT, Bommeli, Suiza) que detecta anticuerpos a B. ovis en suero y presenta una sensibilidad de $82.9 \%$ y una especificidad de $91.4 \%$ (Álvarez et al., 2007).

\section{Análisis de los Datos}

Los datos se analizaron en una tabla de contingencia de $2 \times 2$, obteniéndose el valor de Kappa, que indica el grado de concordancia entre ambas técnicas, según el Cuadro 1. En el análisis se empleó el software estadístico Win Episcope 2.0.

Para analizar la asociación estadística entre las dos variables se utilizó el método de Fisher exacto, método que permite analizar si dos variables están asociadas cuando la muestra es demasiado pequeña y no se cumplen las condiciones necesarias para la aplicación del Chi Cuadrado (Pértega y Fernández, 2004). 
Cuadro 2. Resultados comparativos entre la prueba de ELISA para B. ovis y la palpación testicular para el diagnóstico de brucelosis

\begin{tabular}{ccccc}
\hline & & \multicolumn{2}{c}{ ELISA } & \multirow{2}{*}{ Total } \\
\cline { 2 - 4 } & & + & - & \\
\hline Palpación & + & 2 & 10 & 12 \\
testicular & - & 3 & 25 & 28 \\
\hline Total & & 5 & 35 & 40 \\
\hline
\end{tabular}

\section{Resultados}

Cinco de los 40 carneros resultaron seropositivos a la prueba de ELISA, lo cual equivale a una seroprevalencia de $12.5 \%$; mientras que los resultados de la palpación testicular muestran 12 carneros positivos $(30 \%)$. De estos últimos, cinco presentaron aumento de tamaño en ambos testículos, cinco con aumento de tamaño de un testículo, y dos con atrofia testicular.

El nivel de concordancia entre la palpación testicular y la prueba de ELISA fue pobre $(\mathrm{k}=0.0714)$, no habiendo diferencia estadística entre ambas técnicas $(\mathrm{p}=0.6266)$. La comparación entre las dos pruebas se muestra en el Cuadro 2.

\section{Discusión}

El tamaño inicial de la muestra fue bastante pequeño y la frecuencia de animales positivos a la prueba serológica fue relativamente baja, de allí que es difícil sacar conclusiones válidas.

No existe mucha información sobre brucelosis ovina diagnosticada a través de ELISA en la VIII Región de Chile. Arévalo Hernández (2004) determinó una frecuencia de $34 \%$ de animales seropositivos $(n=876)$ en la en la XI Región, en tanto que Álvarez et al. (2007) reporta $82.9 \%$ ( $\mathrm{n}=82$ carneros) y $91.4 \%$ de seropositividad $(n=421)$ en la Región de Magallanes. Por otro lado, Pérez (2010) no encontró muestras positivas en una población de 79 animales en la Comuna de Cauquenes, VII Región, posiblemente debido al pequeño tamaño de los predios y a la frecuencia de recambio de carneros.

En relación al examen clínico por palpación testicular, solo se dispone de los estudios de Arévalo Hernández (2004) en la XI Región, donde encontró $33.6 \%$ de carneros con alteraciones testiculares $(\mathrm{n}=853)$ y el trabajo de Pérez (2010), quien encontró el 6.3\% de animales con estas alteraciones. Por otro lado, Zamora et al. (1977), en un estudio en la X Región reportó $14.6 \%$ de positivos dentro de una población de 1832 carneros.

El bajo nivel de concordancia obtenido coincide con los resultados de otros investigadores (Arévalo Hernández, 2004; Pérez, 2010), pudiendo deberse a los problemas inherentes a la palpación, ya que no todos los animales infectados con B. ovis presentan epididimitis (OIE, 2004); además que puede ocurrir la presencia de otros agentes causantes de epididimitis y orquitis, tales como Corynebacterium pseudotuberculosis y Staphylococus aureus (Zamora et al., 1977).

Los resultados señalan que en el diagnóstico de epididimitis en los carneros producida por $B$. ovis se requiere realizar no solo la palpación testicular, sino además una prueba serológica confirmatoria, especialmente cuando las prevalencias son relativamente bajas.

\section{Literatura Citada}

1. Álvarez JF, Veneros R, González O. 2007. Validación operacional de un ELISA comercial para Brucella ovis, Chile. Arch Med Vet 39: 275-279. doi: 10.4067/S0301-732X2007000300012. 
2. Arévalo Hernández S. 2004. Determinación de brucelosis ovina (Brucella ovis) en predios de la Undécima región de Chile. Tesis de Médico Veterinario. Valdivia: Universidad Austral de Chile. $31 \mathrm{p}$.

3. Chacón T, Naranjo P. 2007. Términos de referencia para el control de la brucelosis ovina (BO) en la Región de Aysén. En: Boletín Veterinario Oficial, BVO N. ${ }^{\circ}$ 8. Servicio Agrícola y Ganadero Santiago, Chile. 9 p. [Internet]. Disponible en: http://www2.sag.gob.cl/Pecuaria/bvo/BVO_8_I_semestre_2007/ a r t i c u los / T R _ con t rol_ B_OVINA_XI_reg.pdf

4. [INE] Instituto Nacional de Estadística. 2007. Censo agropecuario. Chile. $214 \mathrm{p}$.

5. [OIE] Organización Mundial de Sanidad Animal. 2013. Manual de las pruebas de diagnóstico y de las vacunas para los animales terrestres. Sección 2.7. Enfermedades de la Lista de la OIE y otras enfermedades de importancia para el comercio internacional. Cap. 2.7.9. Epididimitis ovina (Brucella ovis). $7^{\mathrm{a}} \mathrm{ed}$. 1404 p. [Internet]. Disponible en: http:// www.oie.int/fileadmin/Home/esp/ $\mathrm{Healt} \mathrm{h}$ _ s t a n d a r d s / t a h m/ 2.07.09_OVINE_EPID.pdf

6. Paolicchi F. 2001. Epididimitis ovina por Brucella ovis: lesiones genitales y respuesta antiespermática. Rev Med Vet 82: 86-88.

7. Pérez P. 2010. Comparación entre palpación testicular y la prueba serológica
ELISA indirecta en la detección de brucelosis ovina en predios de la Comuna de Cauquenes. Tesis de Médico Veterinario. Talca, Chile. Universidad Santo Tomás. $56 \mathrm{p}$.

8. Pértega S, Fernández S. 2004. Asociación de variables cualitativas: El test exacto de Fisher y el test de Mcnemar. España. [Internet]. Disponible en: http:// www.fisterra.com/mbe/investiga/fisher/ fisher.pdf

9. Pinochet L, Crempien C, Sánchez M, Lopetegui P. 1987. Brucelosis ovina: estudio de prevalencia en hembras y su relación con la infección en carneros. Agric Téc 47(2): 148-151.

10. Robles C. 1998. Epididimitis contagiosa de los carneros por Brucella Ovis. Rev Med Vet 79(1): 67-71.

11. Robles C. 2008. Brucelosis en carneros por Brucella ovis. Bariloche: Instituto Nacional de Tecnología Agropecuaria - INTA EEA Bariloche. 27 p.

12. Schoenian S. 2011. Sheep 201. A beginer's guide to raising sheep. [Internet]. Disponible en: http:// www.sheep101.info/201/

13. Tamayo R, Valentín H, Schoebitz $R$. 1989. Determinación de anticuerpos a Brucella ovis en ovinos de la $\mathrm{X}$ región de Chile. Arch Med Vet 21(1): 22-28.

14. Zamora J, Chahuan E, Polette M, Alonso O, Kruze J, Hervé M. 1977. Brucella ovis y otros agentes etiológicos en epididimitis y orquitis infecciosa ovina. Arch Med Vet 9(2): 94-99. 